\title{
Effect of Applying Exercise Movement Technique by Physical Therapist on Quality of Life in Breast Cancer Survivors: Meta- analysis
}

\author{
Kwang Min Nam', Tae Lim Yoon², Han Na Kim³ \\ 'The Master's Course, Department of Physical Therapy, College of Health \& Medical Science, Cheongju University, Cheongju; ${ }^{2}$ Department of \\ Physical Therapy, College of Health \& Medical Science, Cheongju University, Cheongju; ${ }^{3}$ Department of Dental Hygiene, College of Health \& \\ Medical Science, Cheongju University, Cheongju, Korea
}

Purpose: This study identified the effects of physical therapists on the quality of life when applying exercise-based movement techniques to breast cancer survivors.

Methods: To conduct meta-analysis, 186 RCT studies were searched in five databases (RISS, PubMed, CINAHL, Medline, and Cochrane Library), without limitation, for the year of publication, and papers published in April 2018 were selected. Four studies met the inclusion criteria and were selected for meta-analysis based on the risk of bias. The basic demographic data, athletic characteristics, and outcome data were extracted from all included clinical trials. The data were analyzed using the RevMan 5.2 program.

Results: As a result of meta-analysis, exercise-based movement techniques applied by the control group (Pilates, yoga, tai chi, and qigong) or physical therapists showed no significant difference in the impact on the quality of life of breast cancer survivors.

Conclusion: In this study, exercise-based movement techniques mediated by control groups or physical therapists showed no significant difference in the quality of life of breast cancer survivors, but the types and duration of exercise in each study varied, and the number of subjects was small. Considering randomized studies, more randomized studies will be needed to draw conclusions.

Keywords: Exercise Movement Techniques, Physical Therapist, Breast Neoplasm, Quality of Life

\section{서 론}

유방암은 한국 여성에게서 두 번째로 많은 암으로 2008년에 비해 2012년에 발생률이 20\% 이상 빠르게 증가하고 있다.' 암환자들에게 운동은 신체적, 사회적, 심리적으로 긍정적인 개선효과를 얻을 수 있 는 중재로 80년대 후반부터 적용되었으며 이로 인해 암 생존자 수는 지속적으로 증가하고 있다. ${ }^{2}$ 유방암의 경우 다른 일반적인 암보다 생 존율이 횔씬 뛰어나다. ${ }^{3}$ 이러한 유방암 생존자의 사망률, 재발률을 낮 추는 긍정적인 방법으로 신체활동을 증가시키는 것이 중요하다는 연 구가 많이 보고되었다. 4.5 따라서 현재 운동 중재는 암 수술 전후에서 항암치료 및 재활, 생존기까지 전반에 걸쳐 적용되고 있다. ${ }^{6}$

유방암 환자에게는 주로 상지기능 장애가 있으며 어깨 통증, 운동 범위의 제한, 부종 및 운동 약화가 전형적으로 나타난다. 일반적으로 수술부위를 보호하려는 경향을 보이고 수술 측 어깨의 피부, 근육 및

Received Dec 31, 2019 Revised Feb 10, 2020

Accepted Feb 29, 2020

Corresponding author Tae Lim Yoon

E-mail free0829@gmail.com
힘줄을 포함하는 어깨 주위 조직의 움직임을 제한하며, 이러한 제한 은 일상생활활동에 어려움을 초래할 수 있는 주요 기능 장애이다.3,7.8 신체활동의 긍정적인 효과로는 신체기능 향상, 통증 완화, 스트레스 감소에 큰 도움이 될 뿐만 아니라 유방암 예방, 진단, 수술, 회복 및 재 발을 감소시키는데 도움이 되며, 수술 이후 신체적, 사회적, 심리적 전 반적인 증상 완화에 도움을 준다.911 과거부터 현재까지 운동과 신체 활동은 유방암 생존자가 지각하는 중요한 결과인 삶의 질 ${ }^{10}$ 을 향상시 키기 위해 효과적이고 보완적인 중재로 사용되어지고 있다. '훌륭한 재활 프로그램은 수술 후 좋은 결과를 나타내며, 환자의 기능적인 활 동을 증가시켜 삶의 질을 향상시킬 수 있는 잠재력을 제공한다. ${ }^{8}$

운동과 신체활동과 관련하여 많은 동작중심 운동기술은 비교적 저렴하고 접근이 용이하다. 동작중심운동기술(exercise movement technique)이란 개인의 신체적 및 생리적인 상태를 증진, 유지 또는 회 복시키는 데 사용될 수 있는 신체 활동의 방법 또는 프로그램12으로
Copylight (02020 The Korean Society of Physical Therapy

This is an Open Access article distribute under the terms of the Creative Commons Attribution Non-commercial License (https:// creativecommons.org/license/by-nc/4.0.) which permits unrestricted non-commercial use, distribution, and reproduction in any medium, provided the original work is properly cited. 
서 필라테스, 요가, 태극권, 기공 등이 여기에 포함하는 용어이다. 이 러한 기술들은 암 생존자들의 기능을 향상시키는 잠재력을 제공하 며 통합 전신 운동을 촉진하고 동시에 힘, 조정, 균형, 자세, 유연성 및 운동 의식의 강화라는 중요한 이점을 제공한다. ${ }^{13}$ 그렇지만 $\mathrm{Heo}^{14}$ 의 최근 연구에서 유방암 생존자들의 자가관리 지지 경험에 의하면 참 여자들은 지속적인 자가관리를 할 수 있도록 각자의 상황에 적합한 전문기관의 도움을 필요로 한다. 그러나 국내 암분야에서 권위있는 기관의 하나인 국가 암정보센터에서도 '보완대체요법 바로 알기라는 보완대체요법의 종류와 부작용 및 효과에 대한 간단한 소개 차원의 내용만 안내하고 있을 뿐, 유방암 생존자가 현실적으로 활용 가능한 전문적인 정보가 없다. 동작중심 운동기술은 의료인이 아닌 일반자 격증을 가진 사람의 지도하에 이루어지는데 의료인인 물리치료사가 대체운동을 지도할 때 환자에게 더 적합하고 효과적인 대체운동 프 로그램을 시행할 수 있을 것이다.

한국에서는 40 대 젊은 유방암 환자의 발생률이 높은 편이고 40 세 이하 환자도 약 $11 \%$ 를 차지하는데 이것은 서구에 비해 2 배 이상 높은 발생률을 나타낸다. 앞으로 한국 여성에게 맞는 유방암 예방과 조기 검진, 진단과 치료, 치료 후 회복에 대한 프로그램 마련이 더 중요함 을 의미한다. 동작중심 운동기술의 많은 장점에도 불구하고, 우려를 표명하거나 논의하기를 꺼려한다. 또한 특정 운동내에서 광범위한 이 질성을 보이며, 실무자 전문 지식 및 인증의 불일치 뿐만 아니라 실무 자에게 암 집단 고유의 취약성에 대한 정도도 문제가 될 수 있다. ${ }^{13}$ 아 직까지 유방암 환자에게 적용한 동작중심 운동기술에 대한 메타분 석연구는 전무한 실정이다. 유방암 생존자들의 운동중재와 관련된 개별적 연구들의 결과가 일관되지 못하거나, 서로 상충되는 결과가 도출되었기 때문에 운동의 중재효과에 대한 종합적인 분석이 필요할 것으로 사료된다. 정보를 제공하는 데 있어 과학적인 연구결과를 바 탕으로 전문가들의 지식과 식견을 더하여 생존자들에게 필요한 실 질적인 맞춤형 가이드라인이 제작되고 배포되어야 할 것이다. ${ }^{14}$

본 연구의 목적은 유방암 생존자에게 물리치료사가 동작중심 운 동기술을 적용 시 삶의 질에 미치는 영향에 대한 메타분석을 실시하 여, 효과의 정도를 파악하고 문헌 고찰을 통하여 이들에게 더욱 효과 적인 동작중심 운동기술 프로그램 제공에 도움이 되고자 한다.

\section{연구 방법}

\section{1. 연구설계}

본 연구는 동작중심 운동기술이 유방암을 가진 여성의 삶의 질에 미 치는 영향을 확인하기 위한 메타분석연구이다.

\section{2. 자료 선정 및 검색}

\section{1) 자료의 선정기준 및 배제기준}

본 연구는 핵심질문 형식 PICOTS-SD (Participants, Intervention, Comparisons, Outcomes, Timing of outcome, Setting, Study Design)에 따라 대상연구 선정기준을 구성하였다.

연구참여자(P)는 '유방암 진단을 받은 여성', 중재방법(I)은 '운동기 술, 대조군(C)은 '중재를 받지 않은 군' 혹은 '보존적 치료를 받은 군' 결 과 $(\mathrm{O})$ 는 '운동중재의 효과인 삶의 질', 결과 측정 시점 $(\mathrm{T})$ 은 '운동중재 후', 세팅(S)은 '병원' 또는 '지역사회', 연구설계(SD)는 '무작위 대조군 연 구(Randomized Controlled Trial, RCT) 혹은 '비 무작위 대조군 연구 (Non-Randomized Controlled Clinical Trial, NRCCT)로 설정하였다.

메타분석 대상논문의 선정기준은 1) 실험군과 대조군의 평균값 또 는 표준편차, 검정 통계량 값 또는 신뢰구간이 제시되어 효과크기를 산출할 수 있는 연구, 2) 출판편의를 최소화하기 위하여 출판된 논문 에 학위논문을 포함하되, 학위논문이 학술지에 출판된 경우 학술지 연구를 우선적으로 채택하였다. 대상논문 배제기준은 1) 비실험연구, 2) 운동중재를 하지 않은 경우, 3) 유방암 환자만을 대상으로 하지 않은 경우, 4 ) 종속변수로 삶의 질을 측정하지 않은 논문으로 선정하였다.

\section{2) 자료 검색}

출판 년도 제한 없이 2018년 5월부터 6월까지 검색과 수집이 이루어 졌으며, 추가로 2019년 3월 1일부터 31일까지 검색하고 수집하였다. 국 내 데이터베이스는 한국교육학술정보원(Korea Education and Research Information Service, KERIS)에서 제공하는 학술연구정보서비 스(Research Information Sharing Service, RISS)를 검색하였고, 국외 데 이터베이스는 Medline, CINAHL (Cumulative Index of Nursing and Allied Health), Pubmed, EMBASE, Cochrane Library를 이용하여 검색하 였다.

연구대상 및 중재로부터 핵심질문의 구성요소인 주요 개념어를 도 출하여 검색 전략을 구성하였다. 국내 데이터베이스에서는 '운동 기 술, '요가, '필라테스, '태극권', '기공'과 '암 생존자, '유방암', '유방절제 술,'액와 절제술, 그리고 삶의 질', '기능적 평가,' '기능적 능력'을 조합 하여 검색 하였고, 국외 데이터베이스에서는(((tai ji [MeSH] or yoga [MeSH] or qi gong [MeSH] or Exercise Movement Techniques [MeSH] OR pilates [tiab] )) and ((((cancer survivor [MeSH Terms]) or breast neoplasm [MeSH Terms]) or mastectomy [MeSH Terms]) or axillary dissection [MeSH Terms] )) and (((quality of life [MeSH Terms]) or functional ability [MeSH Terms]) or functional assessment [MeSH Terms])의 용어 들을 병합하여 검색하였다.

동작중심 운동기술과 관련된 주제어로 '요가, '필라테스, '태극권', '기공’을 포함시켰다. 또한 검색된 논문의 참고문헌을 통해 자료를 보 
완적으로 수집하였다. 각 데이터베이스의 통제어와 핵심질문의 구성 요소인 연구대상과 중재 및 연구설계로부터 도출된 주요 개념어를 함께 활용하고 and, or, not과 같은 불리언 연산자(Boolean operators) 및 *, \$, \#, ? 등의 절단검색(truncation) 기능을 사용하여 검색어를 병합 하여 실시하였다.

\section{3. 자료분석}

1) 자료 선별 및 주요결과

(1) 자료의 선별

자료선정과 분석의 전 과정은 연구자 3 인에 의해 수행되었다. 사전에 선정한 선정기준과 배제기준에 따라 독립적으로 검토하였고, 만약 의견이 불일치할 경우 합의점을 찾을 때까지 선정기준과 제외기준에 따라 다시 검토하였다. 데이터베이스를 통하여 검색된 논문의 목록 을 작성하고, 서지반출 프로그램인 조테로(Zotero)를 이용하여 중복 된 논문을 확인 후 제거하였다. 중복논문 제거 후 논문의 제목과 초 록을 검토하여 문헌 선정기준에 부합된 연구인지를 확인하였고, 논 문 제목과 초록만으로 선정기준에 부합되는 연구인지를 판단하기 어 려운 경우에는 논문의 전문을 읽고 검토하여 추가로 환자군과 연구 의 적합성, 원하는 결과값의 사용 유무 등을 확인한 후에 해당문헌의 선정여부를 결정하였다.

\section{(2) 자료의 주요결과 추출}

자료의 주요결과는 저자, 출판연도, 환자군, 중재유형, 중재기간, 중재 빈도, 중재내용, 측정도구, 결과 등을 추출하였다.

\section{2) 통계분석}

(1) 효과크기 분석

본 연구에서 선정된 연구의 중재에 대한 비뚤림 평가 및 효과크기는 Cochrane Library의 Rev Man 5.2 프로그램을 이용하여 메타분석을 수행하고, 그 결과 삶의 질 지표의 결과를 확인하였다. 그 외의문헌의 주요한 내용과 부가적인 수치들은 Excel 프로그램을 이용하여 분석 하였다. 개별연구들의 실험군과 대조군 각각의 대상 환자 수, 평균, 표 준편차에 대한 자료를 추출하였다. 삶의 질 지표인 유럽암연구치료 기구(European Organisation for Research and Treatment of Cancer, EORTC)의 평균값을 이용하여 수량적인 메타분석을 시행하였으며 삶의 질 지표에 대한 효과크기를 확인하였다. 모든 연구결과에 대한 효과크기는 전체효과검증 혹은 $95 \%$ 신뢰구간으로 통계적인 의미를 판단하였고 유의수준은 5\%를 기준으로 하였다. 효과크기의 $95 \%$ 신 뢰구간에 0 (영)이 포함되지 않으면 효과 크기가 유의한 것으로 해석 하였다.
(2) 이질성 검사

선정된 개별연구의 효과크기들이 모집단의 효과크기를 잘 반영하는 지 여부를 확인하기 위해, 전체 관찰된 분산인 Q값을 산출하여 카이 제곱 검정을 하였으며, 유의수준 5\% 미만으로 하여 I-squared $\left(\mathrm{I}^{2}\right)$ 값을 산출하였다. $\mathrm{I}^{2}$ 은 효과크기의 이질성을 나타내는 지수로 총 분산에 대한 실제 분산의 비율을 나타낸다. Q값에 대한 유의확률이 0.10 이 하이고, $I^{2}$ 가 $50 \%$ 이상인 경우 효과크기의 이질성은 상당하다고 판단 한다.

\section{결 과}

\section{1. 자료선정}

국내 데이터 베이스 RISS에서 3편이 검색되었고, 국외 데이터 베이스 Pubmed 54편, Medline 17편, CINHAL 19편, Embase 43편, Cochrane Library 50편이 검색되었다. 조테로 프로그램으로 중복여부를 확인하 였고, 검색된 논문 총 186 편 중 105 편을 제거하였다. 선정기준과 배제 기준에 따라 남은 81 편의 논문의 제목과 초록을 검토하여 53 편의 연 구를 배제하였다. 이후 남은 28편의 논문 전문(full-text)을 읽고 적합 여부를 확인하였고, 총22편의 논문을 선정하였다. 이중 종속변수가 같은 최종 3 편의 논문을 메타분석 하였다(Figure 1).

\section{2. 연구의 질 평가}

문헌 선별과정에서 선정된 3편을 대상으로 연구 비뚤림 위험평가를

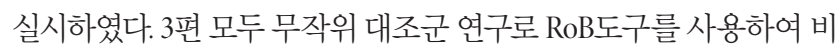
뚤림 위험을 평가하였다. 그 결과 3편의 문헌 모두 performance bias항 목의 참가자에 대한 눈가림영역 비뚤림 위험이 높고, 그 다음으로 2편 의 문헌에서 detection bias항목의 결과 평가에 대한 눈가림 영역 비뚤 림 위험이 높은 것으로 나타났다(Figure 2).

\section{3. 분석대상 논문의 일반적인 특성}

메타분석한 논문 3편의 일반적 특성은 다음과 같다. 3 편(100\%) 모두 학술지에 출판된 논문이었다. 연구 대상자의 유형은 유방암의 단계 로 나눈 환자를 대상으로 한 연구가 2편(66.6\%), 유방암 수술 이후환 자를 대상으로 한 연구가 1편(33.3\%)이었다. 3 편(100\%) 모두 결과변수 인 $\mathrm{QOL}$ 를 측정한 도구는 $\mathrm{EORTC}$ 이었다. 총 중재기간은 6주 1편 (33.3\%) 8주가 2편(66.6\%)으로 나타났다. 회기 별 중재시간은 60분 실 시하는 경우가 2 편(66.6\%), 50 분 실시하는 경우 1편(33.3\%)이었다. 주당 중재빈도는 1주를 기준으로 3회 2편(66.6\%), 1회 1편(33.3\%)이었다. 운 동중재의 유형은 필라테스(pilates) 1편(33.3\%), 그 외 2편(66.6\%)이었다 (Table 1). 3 편 연구의 참여자 수는 총 173 명으로 실험군과 대조군이 각 각 94 명과 79 명이었다. 


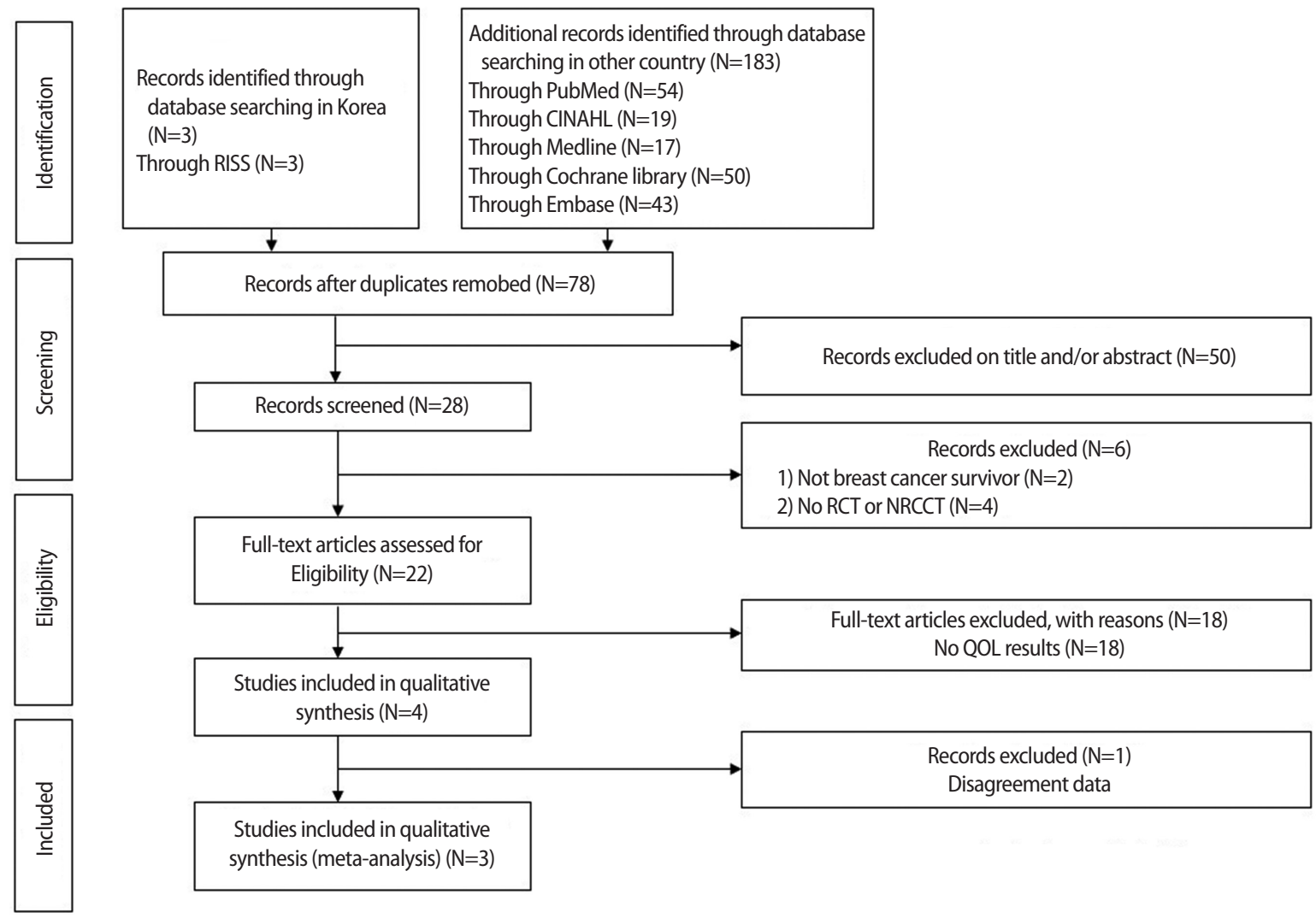

Figure 1. Study flow diagram. RCT: randomized controlled trial, NRCCT: non-randomized controlled clinical trial.

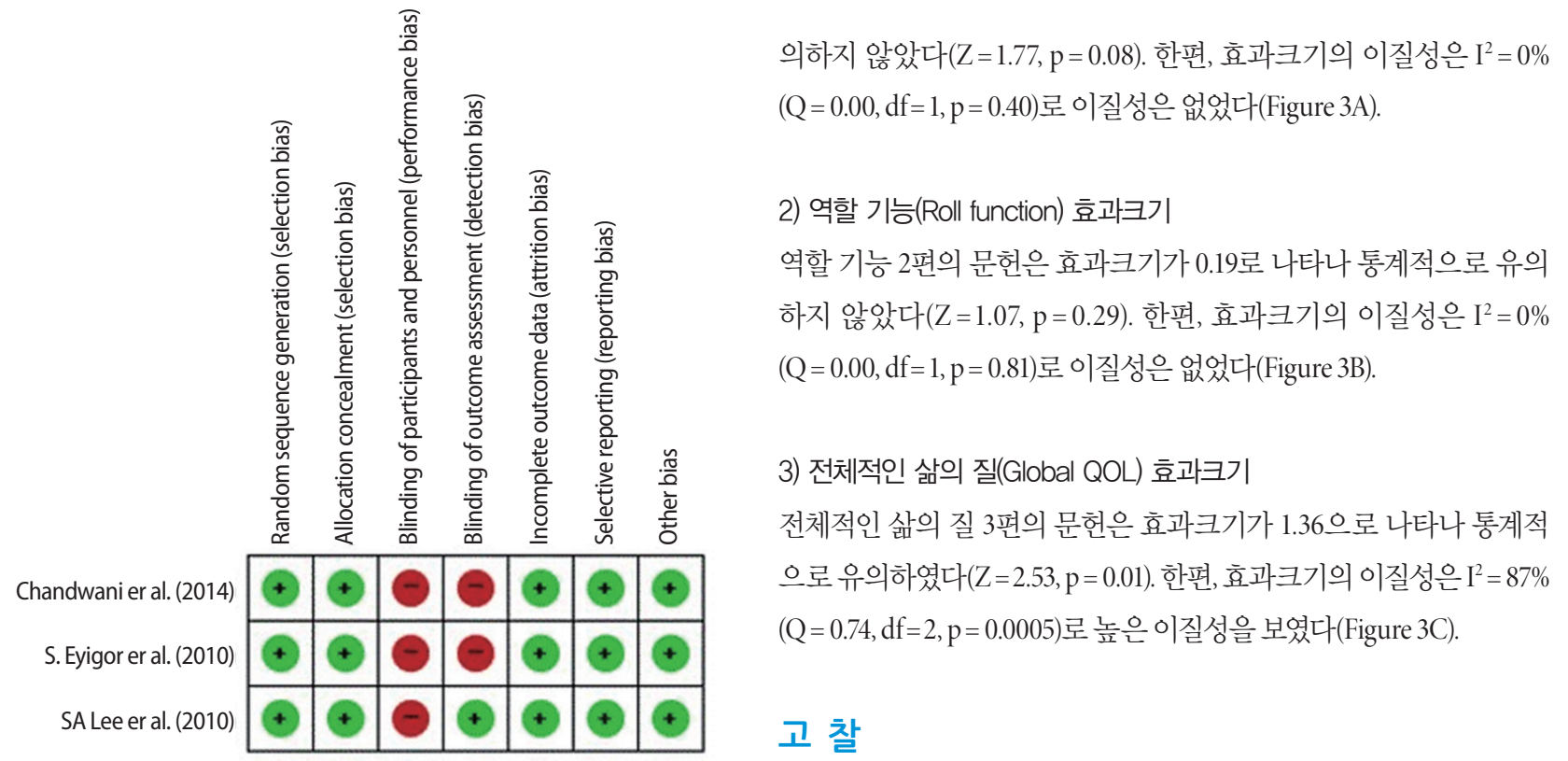

Figure 2. Risk of bias for included study.

\section{4. 결과변수별 효과크기}

1) 신체적 기능(Physical function) 효과크기

신체적 기능 2 편의 문헌은 효과크기가 0.31 로 나타나 통계적으로 유

한국 여성에게 맞는 유방암 예방과 조기검진, 진단과 치료, 치료 후 회복에 대한 프로그램이 중요함에도 불구하고 아직까지 유방암 환 자에게 적용한 동작중심 운동기술에 대한 메타분석연구는 전무한 실정이다. 따라서 이 연구에서는 유방암 생존자에게 물리치료사가 
Table 1. Descriptive summary of 4 studies

\begin{tabular}{|c|c|c|c|c|c|c|c|c|}
\hline \multirow{2}{*}{$\begin{array}{l}\text { Author } \\
\text { (year) }\end{array}$} & \multirow{2}{*}{$\begin{array}{l}\text { Study } \\
\text { design }\end{array}$} & \multicolumn{2}{|c|}{ Participants } & \multicolumn{3}{|c|}{ Intervention } & \multirow{2}{*}{$\begin{array}{l}\text { Outcome } \\
\text { measure }\end{array}$} & \multirow[b]{2}{*}{ Outcome } \\
\hline & & $\begin{array}{c}\text { Number of } \\
\text { object }\end{array}$ & $\begin{array}{l}\text { Medical } \\
\text { condition }\end{array}$ & $\begin{array}{c}\text { Study period } \\
\text { (week) }\end{array}$ & $\begin{array}{l}\text { Frequency } \\
\text { of a session }\end{array}$ & $\begin{array}{l}\text { Exercise } \\
\text { program }\end{array}$ & & \\
\hline $\begin{array}{l}\text { Eyigor et.al. } \\
\text { (2010) }\end{array}$ & RCT & $\begin{array}{l}42(27,15) \\
\mathrm{M} \text { age }=49\end{array}$ & $\begin{array}{l}\text { Breast cancer } \\
\text { stages 0- IIIIb }\end{array}$ & 8 & $\begin{array}{l}\text { Three times } \\
\text { a week }\end{array}$ & $\begin{array}{l}\text { Pilates } \\
\text { - Warm up } \\
\text { - Pilates exercise } \\
\text { - Relaxation }\end{array}$ & $\begin{array}{l}\text { EORTC } \\
\text { QLQ-C30 } \\
\text { BDI } \\
\text { BFI }\end{array}$ & $\begin{array}{l}\text { After exercise program Improvement } \\
\text { observed EG in 6MWT, BDI, EORTC QLQ- } \\
\text { C30 \& BR23 functional scores }(<0.05) \text {. } \\
\text { Significant differences only EG 6MWT } \\
(<0.05) \text {. } \\
\text { After exercise program No significant } \\
\text { improvement observed CG comparison to } \\
\text { the pre exercise program }(>0.05) \text {. }\end{array}$ \\
\hline $\begin{array}{l}\text { Lee et al. } \\
\text { (2010) }\end{array}$ & $\begin{array}{l}\text { RCT } \\
\text { pilot }\end{array}$ & $\begin{array}{l}21(11,10) \\
M \text { age }=47\end{array}$ & $\begin{array}{l}\text { After breast } \\
\text { cancer surgery }\end{array}$ & 8 & $\begin{array}{l}\text { Once } \\
\text { a week }\end{array}$ & $\begin{array}{l}\text { Scapula-oriented } \\
\text { Shoulder exercise } \\
\text { - 5min Warm up } \\
\text { - 40min Stretch \& } \\
\text { Strength exercise } \\
\text { - 5min Cool down }\end{array}$ & $\begin{array}{l}\text { EORTC-C30 } \\
\text { BDI }\end{array}$ & $\begin{array}{l}\text { EG improvements in Pain, Physical } \\
\text { function, Social function, and Global QOL. } \\
\text { General exercise improved fatigue and } \\
\text { ROM. } \\
\text { Significant improvements in the EG Global } \\
\text { QOL }(p=0.067) \text { \& Strength of Ext rot } \\
(p=0.001)\end{array}$ \\
\hline $\begin{array}{l}\text { Chandwani et al. } \\
\text { (2014) }\end{array}$ & RCT & $\begin{array}{l}110(56,54) \\
M \text { age }=52\end{array}$ & $\begin{array}{l}\text { Breast cancer } \\
\text { stages 0- III }\end{array}$ & 6 & $\begin{array}{l}\text { Three times } \\
\text { a week }\end{array}$ & $\begin{array}{l}\text { Stretch ex } \\
\text { - Stretches in a } \\
\text { stepped } \\
\text { approach } \\
\text { approximated } \\
\text { gross movements } \\
\text { of the yoga }\end{array}$ & $\begin{array}{l}\text { SF-36 } \\
\text { PSQI } \\
\text { CES-D }\end{array}$ & $\begin{array}{l}\text { YG group significantly PCS scores } \\
1,3 \text { months }(p=0.01, p=0.01) \text {. } \\
1,3,6 \text { months } Y G \text { group greater increases } \\
\text { in physical functioning compared with } \\
\text { both } S T \text { and } W L \text { groups }(<0.05) \text {, with ST } \\
\text { and } W L \text { differences } 3 \text { months }(<0.02) \text {. } \\
\text { YG and } S T \text { groups reduction in fatigue } \\
(<0.05) \text {. } \\
\text { No differences for mental health and sleep } \\
\text { quality. }\end{array}$ \\
\hline $\begin{array}{l}\text { Yagli, Ulger } \\
\text { (2010) }\end{array}$ & RCT & $\begin{array}{l}20(10,10) \\
M \text { age }=68\end{array}$ & $\begin{array}{l}\text { Breast cancer } \\
\text { stages I-II }\end{array}$ & 8 & $\begin{array}{l}\text { Once } \\
\text { a week }\end{array}$ & $\begin{array}{l}\text { Yoga } \\
\text { - } 15 \text { min Warm-up } \\
\text { \& Breathing } \\
\text { exercise } \\
-15 \text { min Asanas } \\
\text { yoga } \\
\text { - } 30 \text { min } \\
\text { Relaxation \& } \\
\text { Meditation in } \\
\text { supine position }\end{array}$ & $\begin{array}{l}\text { BDI } \\
\text { NHP } \\
\text { VAS }\end{array}$ & $\begin{array}{l}\text { QOL score after Yoga \& Exercise program } \\
\text { better than before }(<0.05) \text {. } \\
\text { NHP \& subcategories ER, SI, S, PA Signifi- } \\
\text { cant improvements in the EG }(<0.05) \text {. } \\
\text { EL, P scores no significant improvement } \\
\text { ( }>0.05) \text {. } \\
\text { Significant improvement All parameters be- } \\
\text { tween pre-post treatment value both } \\
\text { group }(<0.05) \text {. } \\
\text { Post-treatment statistically different } \\
\text { Fatigue \& Sleep quality Group } 1(<0.05) \text {. }\end{array}$ \\
\hline
\end{tabular}

RCT: Randomised controlled trial, EORTC QLQ-C30 \& BR23: European organization for research and treatment of cancer quality of life questionnaire-core30 \& breast23, BDI: Beck depression inventory, BFI: Brief fatigue inventory, EG: Exercise group, 6MWT: 6 minute walk test, CG: Control group, EORTC-C30: European organization for research and treatment of cancer core30, QOL: Quality of life, ROM: Range of motion, Ext rot: Extensor rotation, SF-36: Short form survey, PSQI: Pittsburgh sleep quality index, CES-D: Centers for epidemiological studies-depression, YG: Yoga, PCS: Physical component scale, ST: Stretch, WL: Wait list, NHP: Nottingham health profile, VAS: Visual analog scale, ER: Emotional reaction, SI: Social isolation, S: Sleep, PA: Physical activity, EL: Energy level, P: Pain.

동작중심 운동기술을 적용 시 삶의 질에 미치는 영향에 대한 메타분 석을 실시하고자 하였다. 선정기준과 배제기준에 따라 논문의 제목 과 초록을 검토하고 종속변수가 같은 최종 3편의 논문을 메타분석 하였다. 그 결과 전체적인 삶의 질에서만 통계적으로 유의한 효과크 기가 보고되었다. 같은 종속변수는 신체적 기능, 역할 기능, 전체적인 삶의 질이며, 이 3 가지를 분석하였다. 신체적 기능은 오래 걷기, 스스 로 씻기, 침대 생활, 옷 입기 및 식사하기 등의 신체적인 활동이 가능 한지에 관한 내용이다. 역할 기능은 전문적인 신체활동과 관련된 내 용으로서 직장의 일 또는 가사 일에 제한이 있는지 확인하는 내용이 다. 전체적인 삶의 질은 전반적인 신체 상태와 삶의 질이 어떠했는지 에 관한 질문으로 구성되어 있다.

본 연구에서 신체적 기능의 효과크기는 물리치료사가 시행한 동
작중심 운동기술과 비의료인에 의해 시행된 동작중심 운동기술 간 에서는 통계적으로 유의한 차이가 없었다. 일반적 운동과 견갑골 중 심의 운동을 비교한 논문에서 물리치료사가 시행한 어깨 운동은 통 계적으로 유의하지 않지만 통증감소에 기여할 수 있다고 서술하고 있다. 수술 후 어깨 관절의 운동학적 변화가 있기에 운동을 함으로써 어깨의 운동 범위와 강도가 증가하는데 영향을 줄 수 있다고 한다. ${ }^{3}$ 스트레칭 운동과 요가 운동을 비교한 논문에서는 물리치료사가 시 행한 요가 운동이 단기적으로 점수의 증가가 있었기에 임상적인 중 요성을 강조하였다. 그러나 장기적인 부분에서는 유의하지 않았다. ${ }^{15}$ 물리치료사가 시행한 동작중심 운동기술과 비의료인에 의해 시행된 동작중심 운동기술이 신체적 기능에 미치는 영향을 암환자에게서 직접적으로 비교한 연구는 없었지만, 무릎 골관절염 환자에게 적용 


\begin{tabular}{|c|c|c|c|c|c|c|c|c|c|c|}
\hline \multicolumn{10}{|c|}{ Physical function result } & \\
\hline \multirow[b]{2}{*}{ Study or Subgroup } & \multicolumn{3}{|c|}{ Experimental } & \multicolumn{3}{|c|}{ Control } & \multirow{2}{*}{\multicolumn{2}{|c|}{$\begin{array}{c}\text { Std. Mean Difference } \\
\text { Weight } \quad \text { IV, Randem.95\% Cl }\end{array}$}} & Std. Mean Difference & \\
\hline & Mean & so & Iotal & Mean & So & Tetal & & & IV Randem. $95 \% \mathrm{Cl}$ & \\
\hline Chandwani et al. (2014) & 46 & 1.1 & 56 & 45.7 & 1.3 & 54 & $84.8 \%$ & $0.25[-0.13,0.62]$ & fis & \\
\hline SA Lee et al. (2010) & 86.1 & 4.7 & 11 & 80.7 & 10.2 & 10 & $15.2 \%$ & $0.66[-0.22,1.55]$ & & \\
\hline Total $(95 \% \mathrm{Cl})$ & & & 67 & & & 64 & $100.0 \%$ & $0.31[-0.03,0.66]$ & & \\
\hline $\begin{array}{l}\text { Heterogeneity: Tau }=0.0 \\
\text { Test for overall effect: } Z=\end{array}$ & $\begin{array}{l}\mathrm{Chi}^{2}= \\
1.77(\mathrm{P}\end{array}$ & $\begin{array}{l}0.72, d \\
0.08)\end{array}$ & $f=1(P$ & $P=0.40$ & )$; p^{2}=$ & & & & $\begin{array}{cccc}-2 & -1 & 0 & 1 \\
\text { Favours [control] } & \text { Favours [ }\end{array}$ & erimental] \\
\hline
\end{tabular}

Roll function result

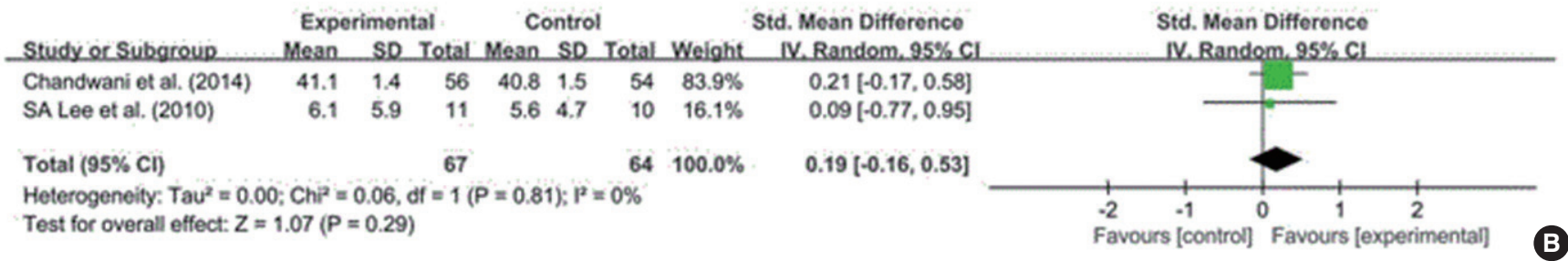

Global QOL result

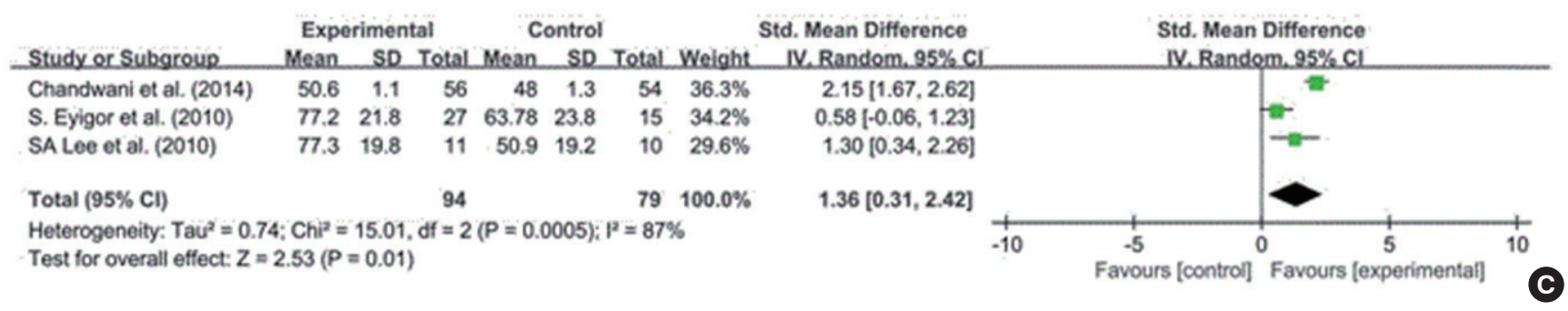

Figure 3. Result.

한 동작중심 운동기술(물리치료와 태극권)의 비교 효과를 52주간 알 아본 선행연구에 따르면, 본 연구의 결과와 비슷하게 물리치료사가 적용한 동작중심 운동기술과 태극권 그룹 간에 골관절염 지수(Western Ontario and Mcmaster Universities Osteoarthritis Index, WOMAC), 신체적 기능 점수(physical function score)와 단문식 건강 설문 조 사-36 (Short Form-36)의 신체적 요소(physical component)에서 유의한 차이를 나타내지 않았다. ${ }^{16}$ 이러한 결과가 나온 이유를 유추해 보자 면 신체적 기능에 주로 영향을 끼치는 신체적인 능력의 향상은 의료 적인 지식에 크게 의존되지 않아서 물리치료사나 비의료인에 의해 시행된 동작중심 운동기술에 별다른 차이점이 없었다고 생각된다. 따라서 물리치료사와 비의료인들 간에 신체적 기능에 미치는 영향 을 통계 분석한 논문의 편수가 많지 않아서 결론을 내리기는 어렵지 만 물리치료사와 비의료인들이 시행한 동작중심 운동기술이 신체적 기능에 미치는 영향에는 차이가 없다.

본 연구에서 역할 기능의 효과크기는 물리치료사가 시행한 동작 중심 운동기술과 비의료인에 의해 시행된 동작중심 운동기술 간에 서는 통계적으로 유의한 차이가 없었다. 본 연구에서 선택된 연구 중 일반적 운동과 견갑골 중심의 운동을 비교한 논문에서 물리치료사 가 시행한 견갑골 특유의 어깨운동이 어깨 장애를 개선하는데 효과
적일 수 있다고 하였으나, 통계적 힘은 강하지 않았고, 심한 통증과 우 울감을 호소하는 장애가 있는 참가자는 제외하였기에 실질적인 기 능 장애를 개선했는지 여부는 확인할 수 없었다. 또한 물리치료사가 시행한 스트레칭 운동과 요가 운동을 비교한 논문에서도 전체적인 신체적 요소 점수는 유의하게 나왔지만 부척도에서는 그 효과성을 나타내기 어려웠다. ${ }^{15}$ 따라서 물리치료사와 비의료인들 간에 역할 기 능에 미치는 영향을 통계 분석한 논문의 편수가 많지 않아서 결론을 내리기는 어렵지만 물리치료사와 비의료인들 간에 역할 기능에 미치 는 영향은 차이가 없다.

본 연구에서 전체적인 삶의 질의 효과크기는 물리치료사가 시행 한 동작중심 운동기술과 비의료인에 의해 시행된 동작중심 운동기 술 간에서는 통계적으로 유의하게 높게 나왔다. 일반적 운동과 견갑 골 중심의 운동을 비교한 논문에서는 물리치료사가 시행한 어깨 운 동은 통계적으로 유의한 차이를 크게 보였다. 통증의 감소와 견갑골 중심의 운동이 어깨의 범위와 강도를 증가시켰고, 또한 암생존자의 관심도 증가로 삶의 질에 현저한 이점을 나타냈다고 말하고 있다. 스 트레칭 운동과 요가 운동을 비교한 논문에서는 물리치료사가 시행 한 요가 운동이 통계적으로 유의한 결과를 나타냈다. 신체적 요소 점 수의 부척도이지만, 주목할 만한 점수를 나타내며 유의한 결과를 보 
여주고 있다. ${ }^{15}$ 추가적으로 유방암 환자에게 물리치료사가 적용한 동 작중심 운동기술(요가)의 효과를 4주간 전. 후 비교한 연구에 따르면 노팅엄 건강 프로파일(Nottingham Health Profile, NHP) 점수에서 유 의한 결과를 나타냈다. ${ }^{17}$ 그러나 한 연구에서는 물리치료사가 시행한 필라테스 운동과 일반적 운동을 비교한 논문에서는 두 군 간에 통계 적으로 유의한 결과를 보이지 않았다. 이러한 상반된 연구결과가 나 온 이유는 유방암 환자의 장기적인 삶의 심리적 영향으로 인한 것일 수 있다고 한다. ${ }^{18}$ 따라서 물리치료사가 시행하는 동작중심 운동기술 이 비의료인이 시행할 때보다 전체적인 삶의 질에 유의한 결과를 나 타낸다고 볼수 있다.

종합적으로 살펴볼 때 오래 걷기, 스스로 씻기, 침대 생활, 옷 입기 및 식사하기 등의 신체적인 활동이나 직장의 일 또는 가사 일 같은 신 체적 기능과 역할 기능을 향상시키는 것은 물리치료사와 비의료인들 간에 유의한 차이를 보이지 않지만 전반적인 삶에 질에는 유의한 차 이를 보였다. 이렇게 물리치료사가 중재를 하는 것이 삶의 질을 더 높 일 수 있던 이유를 살펴보자면, 동작중심 운동기술 중재동안 신체적 인 중재 외의 심리나 교육적인 중재가 이루어졌을 가능성이 있다. 물 리치료사는 의료적인 기술과 지식, 전문성, 친근한 태도 및 효과적인 의사소통 능력으로 환자의 상태에 대한 유용한 설명을 하고, 환자에 게 자기 관리 전략에 대한 교육을 제공하는 효과적인 특성을 가지고 있다. ${ }^{19}$ 이러한 대인 관계 측면에서 의료서비스 제공은 만성 또는 증 상 개선 능력이 제한된 진행성 환자에게 만족도 뿐만 아니라 ${ }^{20}$ 환자 치료의 질 평가에 대한 가장 중요한 요인으로 작용하여 삶의 질에 이 로운 영향을 줄 수 있다. ${ }^{21}$ 추가적으로 물리치료사는 환자에게 적합 한 운동을 제시할 뿐만 아니라 2차적인 손상 등의 위험을 사전에 차 단하며 방지할 수 있는 장점이 있으며, 비의료인들과 달리 선별검사 등의 평가를 진행 후 중재를 진행하는 재활의 핵심적인 구성원 역할 을 담당할 수 있을 것으로 사료된다. 이는 환자의 운동 프로그램 참여 를 극대화하고, 장기적인 암 재발 방지에 중요한 요소로 작용할 수 있 는 장점이 있으며, ${ }^{20,22}$ 물리치료사가 유방암 환자에게 동작중심 운동 기술을 적용 시 물리치료사에게 이점이 있을 가능성이 있다.

본 연구에서 유방암 생존자에게 물리치료사가 동작중심 운동기 술을 적용시 삶의 질에 미치는 영향 연구의 제한점은 다음과 같다. 대 상자, 중재의 구성요소, 결과의 구성요소를 통제할 경우 메타분석을 시행할 만한 논문의 수가 부족하였다. 이는 연구의 통계적인 파워가 부족하여 연구결과의 적용을 어렵게 한다. 개별연구에서 활발한 연 구가 이루어져, 분석을 위한 충분한 연구수가 있을 때 분석결과가 더 의미가 있으므로 앞으로 추후 연구들이 축적된다면, 삶의 질에 미치 는 영향에 대한 다각적인 분석이 가능할 것이다. 또한 삶의 질이라는 제한된 종속변수보다 추후 새로운 연구에서는 기능적 활동과 같은 다양한 종속변수를 모색하여 분석해볼 필요가 있다.
이 연구의 목적은 유방암 생존자에게 물리치료사가 동작중심 운 동기술을 적용시 삶의 질에 미치는 영향을 확인하는 것이었다. 분석 된 연구의 수가 부족하기는 하지만 암환자에게 물리치료사와 비의료 인들간에 시행한 동작중심 운동기술의 효과에 대한 차이점을 처음 으로 제시한 연구이다. 이 연구 결과에서는 물리치료사와 비의료인 들이 시행한 동작중심 운동기술의 적용이 신체적 기능과 역할 기능 에 미치는 영향 간에는 차이가 없었지만 부족한 연구수로 인해 확실 한 결론을 내리기는 어려웠다. 유일하게 물리치료사가 시행하는 동 작중심 운동기술이 비의료인이 시행할 때보다 전체적인 삶의 질에 유의하게 높은 효과를 보였는데, 이는 물리치료사는 의료적인 기술 과 지식, 전문성, 친근한 태도 및 효과적인 의사 소통 능력 등이 유방 암 환자에게 동작중심 운동기술을 적용시 물리치료사에게 이점이 있을 가능성을 나타냈다. 따라서 유방암환자에게 동작중심 운동기 술을 적용시 비의료인보다는 물리치료사가 시행하는 것이 환자의 전 체적인 삶의 질을 향상시키위해 추천된다.

\section{REFERENCES}

1. Park SH. 2018 Breast Cancer Facts \& Figures, Korean Breast Cancer Society, 2018:3-4.

2. Smith SL. Physical exercise as an oncology nursing intervention to enhance quality of life. Oncology Nursing Forum. 1996;23:771-8.

3. Lee SA, Kang JY, Kim YD et al. Effects of a scapula-oriented shoulder exercise programme on upper limb dysfunction in breast cancer survivors: a randomized controlled pilot trial. Clin Rehabil. 2010;24(7):600-13.

4. Friedenreich CM, Gregory J, Kopciuk KA et al. Prospective cohort study of lifetime physical activity and breast cancer survival. Int J cancer. 2009; 124(8):1954-62.

5. Holick CN, Newcomb PA, Trentham-Dietz A et al. Physical activity and survival after diagnosis of invasive breast cancer. Cancer Epidemiol Biomarkers Prev. 2008;17(2):379-86.

6. Kim EM. Effects of exercise program for post-op breast cancer survivors: a meta-analysis. Kangwon National University. Dissertation of Master's Degree. 2013.

7. Kim GH, Choe HS, Lee HI et al. The effects of scapular stabilization exercising on dynamic standing balance in stroke patients. J Kor Phys Ther. 2014;2(1):15-20.

8. Yoon HY, Choi JD. Effects of low-intensity scapular stabilization exercise in arthroscopic shoulder surgery patients. J Kor Phys Ther. 2012;24(3): 229-34.

9. Jang HJ, Kim SY, Kwon CS. Relationships between flexed posture, physical performance and psychosocial factors in elderly women. J Korean Soc Phys Ther 2014;26(5):358-64.

10. Kang JI, Jeong DK, Choi H. The effect of fatigue of patients with chronic obstructive pulmonary disease on depression and the health-related quality of life. J Korean Soc Phys Ther 2014;26(4):262-8.

11. Lee JA. Effects of exercise intervention programs for shoulder functionality in korean breast cancer patients: a systematic review and meta- 
analysis. The Korean Journal of Physical Education: Natural Sciences. 2015;54(2):363-75.

12. Pubmed Mesh Database Year introduced: 2002.

13. Ruddy KJ, Stan DL, Bhagra A et al. Alternative exercise traditions in cancer rehabilitation. Phys Med Rehabil Clin N Am. 2017;28(1):181-92.

14. Heo SM, Heo NR. The phenomenological study of self-management intervention among breast cancer survivors: Non-pharmacological approaches. Journal of Korea Academia-Industrial cooperation Society. 2016;17(12):270-84.

15. Wang C, Schmid CH, Iversen MD et al. Comparative effectiveness of tai chi versus physical therapy for knee osteoarthritis: a randomized trial. Ann Intern Med. 2016;165(2):77.

16. Chandwani KD, Perkins G, Nagendra HR et al. Randomized, controlled trial of yoga in women with breast cancer undergoing radiotherapy. J Clin Oncol. 2014;32(10):1058-65.

17. Ülger Ö, Yağlı NV. Effects of yoga on the quality of life in cancer patients.
Complement Ther Clin Pract. 2010;16(2):60-3.

18. Eyigor S, Karapolat H, Yesil H et al. Effects of pilates exercises on functional capacity, flexibility, fatigue, depression and quality of life in female breast cancer patients: a randomized controlled study. Eur J Phys Rehabil Med. 2010;46(4):481-7.

19. Hush JM, Cameron K, Mackey M. Patient satisfaction with musculoskeletal physical therapy care: a systematic review. Phys Ther. 2011;91(1): 25-36.

20. Park SK, Heo JW. Correlation between professionalism, job satisfaction and job performance of the physical therapist. J Kor Phys Ther. 2015; 27(1):12-7.

21. Curry A, Sinclair E. Assessing the quality of physiotherapy services using servqual. International J Health Care QA. 2002;15(5):197-205.

22. Wisotzky, Khanna, Hanrahan et al. Scope of practice in cancer rehabilitation. Curr Phys Med Rehabil Rep. 2017;5(1):55-63. 